\title{
Perspective of violence and crime
}

\author{
The relevance of failure in natural developmental processes and their family correlates for prevention \\ is abundantly clear
}

\section{Introduction}

Violence and crime are popular topics currently in Sri Lanka, with the media giving wide publicity to their prevalence. Along with this major media preoccupation, there is a sense of public helplessness due to the lack of an immediate solution. A wide range of sociocultural causes are thought by various experts to contribute these violent crimes, and no particular social class or group is exempt, either as victims or as perpetrators. The causes given include rapid social change and urbanisation, ineffective law enforcement, civil war, poverty and deprivation, and display of violence on television. Though these circumstances affect many, only a handful of individuals resort to violence, and the majority remain peace loving and law abiding. Most experts agree also that there are individuals in our society with a high potential for violence. They show their antisocial tendency by readily using violence to resolve problems and challenges, and are intolerant and insensitive to rights of other people. How are such individuals different from most others in our society? Is this difference based on a biological predisposition or the past and present experiences? Can the potential for violence be predicted in advance? Are there known effective preventive measures? Can these questions be answered on scientific evidence?

\section{Childhood disorders and adult criminality}

There are many models that describe aggression in human beings. Violent behaviour has been seen as a failure in the natural developmental processes of emotional and behaviour control in oneself with an inability to comply with social restraints [1].

Long term follow up studies from preschool years have shown that the tendency for aggression in adulthood can be recognised as early as the second year in life [2-4]. The early predictive signs identified include seriously disruptive behaviour, temper tantrums, soiling, daytime enuresis, and language, learning and social difficulties. Biological predisposition and social influences are believed to contribute to this adverse prognosis [1]. Hence identifying and understanding such biological and social risk factors in an individual child or groups of children is of paramount importance for preventing adolescent and adult antisocial behaviour through early intervention. But, such behaviours often go unrecognised or untreated, either because they are believed to be "normal" for children, or because the parents do not know from where to get help.

Some childhood disorders are clearly associated with violence, criminality, and drug and alcohol abuse later in adolescence and young adulthood. Adult manifestations include using weapons, group violence and vandalism, failed education, unemployment, marital violence, and child abuse [5]. There is a 2-3-fold higher risk of being diagnosed with these disorders in boys than in girls. Attention deficit hyperactivity disorder (ADHD) and conduct disorder (CD) are two conditions that are included in the diagnostic classification for child psychiatric disorders [6]. They have a prevalence of about $4 \%$ in rural and $9 \%$ in urban populations [7]. Ninety per cent of adult recidivists are believed to have had CD in childhood [5]. ADHD is signified by hyperactivity, attention deficit and impulsive behaviour. The diagnosis of CD is based on the presence of aggression, lack of empathy, cruelty, bullying, noncompliance with authority, lying, stealing and fire setting [6]. ADHD is recognised as a "dysmaturity" of the prefrontal cerebral cortex and subcortical structures such as the basal ganglia [8]. Genetic factors contribute significantly to its causation. Other important causes are intrauterine alcohol exposure, brain injury, and severe social deprivation in preschool life [8]. Twenty per cent of children with ADHD are known to enter adulthood with antisocial personality disorder [9]. Brain imaging studies show also that adults with antisocial personality disorder have frontal cortical deficits [10]. Thus there are grounds to believe that adult antisocial personality disorder is unresolved childhood ADHD. In a large cohort of children identified with conduct problems, $76 \%$ of the boys and $30 \%$ of the girls had a criminal record, a mental disorder, or both by age 30 years [11]. The mental disorder was almost always severe substance abuse. Mental disorders and crime were strongly associated, especially among males, with a history of childhood conduct problems [11].

\section{Family experiences in childhood and adult violence}

There is a wealth of research evidence, from both developed and developing countries on the influence of family and parents on later criminality [5,12,13]. For instance, parents with poor education, a mother under the age of 18 or over the age of 35 at time of birth, family history of criminality, social deprivation, harsh punishments, family conflict, physical abuse, rejection and lack of supervision by parents have all been recognised as predisposing factors to violence. Although the independent contribution of each is small, their cumulative effect is strong [12]. They provide evidence that family based risk factors predispose to adult criminality. Genetically vulnerable children whose parents are antisocial may be particularly susceptible to family influences [5]. The long term effect of child abuse and neglect on adult criminality and violence is another area 
that has been extensively studied. Children who were abused are at risk of becoming perpetrators of physical and sexual abuse themselves later in life.

\section{Prevention}

All primary health care workers and paediatricians have a pertinent role to play in early identification and management of children and families with a high loading of the biological and social risk factors mentioned above. Preventive strategies should target both the children and their parents. For children, improving educational attainment, preventing school failure and drop-out, helping to develop more socially appropriate emotional responses, and improving problem solving skills have all been effective [14]. As for medication, psychostimulant drugs are useful in reducing impulsiveness and aggression, and improving interpersonal behaviour. Antipsychotics can be used in the short term to reduce aggressive behaviour. For parents, training programmes to improve their quality of parenting have been successfully replicated [15]. These focus on establishing positive child-parent interactions, consistent limit setting for unacceptable behaviour, and being effective role models in problem solving. Psychosocial intervention in childhood, medication, and improving the quality of parenting are known to reduce later substance misuse and law breaking behaviour [14]. School-based primary prevention programmes for high risk groups of children include improving reading and writing skills and behaviour modification techniques for disruptive classroom behaviour. Such interventions are likely to have a far greater impact on delinquency and violence than secondary and tertiary prevention programmes such as those of the criminal justice system [16].

\section{Conclusions}

Though socially oriented explanations for violence and crime are favoured by the majority, the relevance of developmental processes and childhood behaviour disorders and their biological and family correlates is clear. The effectiveness of prevention and early intervention strategies is evident and should be used at all possible levels. Health and education services should collaborate to implement community based effective preventive strategies for these children and families.

\section{References}

1. Fonagy P. Towards a developmental understanding of violence. British Journal of Psychiatry 2003; 183: 190-2.
2. Nagin DS, Tremblay RE. Parental and early childhood predictors of persistent physical aggression in boys from kindergarten to high school. Archives of General psychiatry 2001; 58: 389-94.

3. Stevenson J, Goodman R. Association between behaviour at age 3 years and adult criminality. British Journal of Psychiatry 2001; 179: 197-202.

4. Satterfield JH, Schell A. A prospective study of hyperactive boys with conduct problems and normal boys: adolescent and adult criminality. Journal of the American Academy of Child and Adolescent Psychiatry 1997; 36: 1726-35.

5. Scott S. Aggressive behaviour in childhood. British Medical Journal 1998; 316: 202-6.

6. Diagnostic and Statistical Manual of Mental Disorders. ed. IV. Washington DC: American Psychiatric Association, 1994.

7. Rutter M, Cox A, Tupling C, Berger M, Yule W. Attainment and adjustment in two geographical areas. I-The prevalence of psychiatric disorder. British Journal of Psychiatry 1975; 126: $493-509$.

8. McArdle P. Attention-deficit hyperactivity disorder and life-span development. British Journal of Psychiatry 2004; 186: 468-9.

9. Mannuzza S, Klein RG, Bessler A, Malloy P, La Padula M. Adult psychiatric status of hyperactive boys grown up. American Journal of Psychiatry 1998; 155: 493-8.

10. Raine A, Lencz T, Bihrle S La Casse L, Colletti P. Reduced prefrontal grey matter volume and reduced autonomic activity in antisocial personality disorder. Archives of General Psychiatry 2000; 57: 119-27.

11. Kratzer L, Hodgins S. Adult outcomes of child conduct problems: a cohort study. Journal of Abnormal Child Psychology 1997; 25: 65-81.

12. Klevens J, Roca J, Restrepo O, Martinez AM. Risk factors for adult male criminality in Colombia. Criminal Behavior and Mental Health 2001; 11: 73-85.

13. Farrington DP. The Twelfth Jack Tizard Memorial Lecture. The development of offending and antisocial behaviour from childhood: key findings from the Cambridge Study in Delinquent Development. Journal of Child Psychology and Psychiatry 1995; 36: 929-64.

14. Satterfield JH, Satterfield BT, Schell AM. Therapeutic interventions to prevent delinquency in hyperactive boys. Journal of the American Academy of Child and Adolescent Psychiatry 1987; 26: 56-64.

15. Scott S, Spender, Q, Doolan, M, Jacobs B, Aspland H. Multicentre controlled trial of parenting groups for childhood antisocial behaviour in clinical practice. British Medical Journal 2001; 323: 194-7.

16. Rivara FP, Farrington DP. Prevention of violence. Role of the pediatrician. Archives of Pediatrics \& Adolescent Medicine 1995; 149: 421-9.

Hemamali Perera, Senior Lecturer in Psychological Medicine, University of Colombo. Correspondence: E-mail: <hemamali_p@sltnet.lk> (Competing interests: none declared). Received 21 September 2003, and accepted 2 January 2004. 